\title{
Baseline Sensitivity of Ascochyta rabiei to Azoxystrobin, Pyraclostrobin, and Boscalid
}

\author{
K. A. Wise, C. A. Bradley, J. S. Pasche, and N. C. Gudmestad, Department of Plant Pathology, North Dakota State \\ University, Fargo 58105; and F. M. Dugan and W. Chen, United States Department of Agriculture-Agriculture Re- \\ search Service, Department of Plant Pathology, Washington State University, Pullman 99164
}

\begin{abstract}
Wise, K. A., Bradley, C. A., Pasche, J. S., Gudmestad, N. C., Dugan, F. M., and Chen, W. 2008. Baseline sensitivity of Ascochyta rabiei to azoxystrobin, pyraclostrobin, and boscalid. Plant Dis. 92:295-300

Ascochyta rabiei, causal agent of Ascochyta blight on chickpea (Cicer arietinum), can cause severe yield loss in the United States. Growers rely on applications of fungicides with sitespecific modes of action such as the quinone outside inhibiting (QoI) fungicides azoxystrobin and pyraclostrobin, and the carboximide fungicide boscalid, to manage disease. In all, 51 isolates collected prior to QoI fungicide registration and 71 isolates collected prior to boscalid registration in the United States were tested in an in vitro assay to determine the effective fungicide concentration at which $50 \%$ of conidial germination was inhibited $\left(\mathrm{EC}_{50}\right)$ for each isolatefungicide combination. The effect of salicylhydroxamic acid (SHAM) on conidia of A. rabiei in the presence and absence of azoxystrobin also was assessed to determine whether the fungus is capable of using alternative respiration. Five of nine A. rabiei isolates tested had significantly higher $(P \leq 0.05) \mathrm{EC}_{50}$ values when SHAM was not included in media amended with azoxystrobin, indicating that $A$. rabiei has the potential to use alternative respiration to overcome fungicide toxicity in vitro. $\mathrm{EC}_{50}$ values of azoxystrobin and pyraclostrobin ranged from 0.0182 to $0.0338 \mu \mathrm{g} / \mathrm{ml}$ and from 0.0012 to $0.0033 \mu \mathrm{g} / \mathrm{ml}$, with mean values of 0.0272 and 0.0023 $\mu \mathrm{g} / \mathrm{ml}$, respectively. $\mathrm{EC}_{50}$ values of boscalid ranged from 0.0177 to $0.4960 \mu \mathrm{g} / \mathrm{ml}$, with a mean of $0.1903 \mu \mathrm{g} / \mathrm{ml}$. Establishment of these baselines is the first step in developing a monitoring program to determine whether shifts in sensitivity to these fungicides are occurring in the A. rabiei pathogen population.
\end{abstract}

Additional keywords: Didymella rabiei, fungicide resistance

Ascochyta blight, caused by the fungal pathogen Ascochyta rabiei (Pass.) Labr. (teleomorph, Didymella rabiei (Kovatsch.) Arx.), is a limiting disease of chickpea ( $\mathrm{Ci}$ cer arietinum L.) production throughout the world $(18,27)$. In the United States and Canada, chickpea production has decreased in the last decade due to the devastating effects of Ascochyta blight, which is considered to be the most important disease affecting chickpea production in these regions $(5,7,30)$. A. rabiei can spread quickly throughout chickpea fields, causing significant yield losses $(5,30)$. Development of chickpea cultivars with durable resistance has been complicated by the presence of different pathotypes of $A$. rabiei $(5,7)$. Therefore, growers rely on fungicide applications to manage the disease (27).

Corresponding author: C. A. Bradley

E-mail: carlbrad@uiuc.edu

Current address of C. A. Bradley: Department of Crop Sciences, University of Illinois, $1102 \mathrm{~S}$. Goodwin Ave., Urbana 61801.

Accepted for publication 24 September 2007.

doi:10.1094/PDIS-92-2-0295

(C) 2008 The American Phytopathological Society
Two of the most widely used fungicide active ingredients for control of Ascochyta blight in the United States are azoxystrobin (Amistar or Quadris; Syngenta Crop Protection, Greensboro, NC) and pyraclostrobin (Headline; BASF Corporation, Research Triangle Park, NC). Azoxystrobin became available for use on chickpea in the 2002 growing season in areas of the United States where section 18 emergency exemptions were approved for control of Ascochyta blight on chickpea. In 2003, both azoxystrobin and pyraclostrobin received United States Environmental Protection Agency section 3 registrations prior to the growing season. These fungicides are classified as quinone outside inhibitors (QoI) and block electron transport at the quinol-oxidizing site of the cytochrome $\mathrm{bc}_{1}$ complex (complex III) in the mitochondrial respiration chain $(2,10)$. The site-specific mode of action of this chemistry increases the potential for fungicide resistance to develop in the target fungal populations. Several fungal pathogens are reported to have reduced levels of sensitivity to QoI fungicides due to single amino acid substitutions in the cytochrome $b$ site $(6,10,15,16,23)$.

The fungicide boscalid (Endura; BASF Corporation) was registered in 2003 on chickpea for control of Ascochyta blight in the United States, but was not available for use by growers until the 2004 growing season. Boscalid is a novel chemistry in the carboximide group that acts at succinate-ubiquinone reductase (complex II) in the mitochondrial respiration pathway (3). Due to price constraints, this fungicide currently has limited use in chickpea production in the United States; however, the site-specific mode of action increases the likelihood that shifts in fungicide sensitivity will occur in the pathogen population if boscalid use on chickpea becomes more widespread in the future. The first report of fungal resistance to boscalid was published recently by Avenot and Michailides (1), in which Alternaria alternata isolates from pistachio (Pistacia vera) in California were found to be resistant.

Because growers rely heavily on fungicide applications to manage Ascochyta blight, it is important to determine whether the fungal population is changing in response to selection pressure. Isolates of $D$. bryoniae, a pathogen of cucurbits in the same genus as the teleomorph of Ascochyta rabiei (D. rabiei), have been reported to be resistant to the QoI fungicide azoxystrobin $(20,29)$. Because of these reports and the history of QoI resistance in other pathogens, a baseline sensitivity level should be established to facilitate a monitoring program to detect shifts in sensitivity. According to Brent and Holloman (4), there are three reasons to conduct baseline fungicide sensitivity studies: (i) to develop and test an accurate, rapid, reproducible method for determining the degree of sensitivity of large numbers of field samples of major target fungi, so that such a method is readily available for any future monitoring that may be required; (ii) to obtain initial data regarding the range of sensitivity that exists in major target pathogens and major areas of use, to serve as a baseline against which any future measurements of sensitivity can be compared in order to reveal any possible shifts in sensitivity; and (iii) to detect any differences in sensitivity between samples that might, through the buildup of the lesssensitive components, lead to future resistance problems. Jutsum et al. (12) and Russell (26) stressed the importance of determining the range of sensitivities present in target pathogen populations prior to commercialization of the product. Estab- 
lishing a baseline for the carboximide fungicide, boscalid, is a proactive approach to fungicide resistance management and will allow pathogen sensitivity to be monitored if the chemistry use becomes more widespread on chickpea in the United States.

Previous research involving in vitro testing of fungi in the presence of respirationinhibiting fungicides has indicated that some fungi are able to use an alternative respiration pathway to bypass complex III and IV in the mitochondrial respiration chain, allowing fungal spores to germinate even in the presence of high doses of certain fungicides $(22,31,35)$. This phenomenon is observed only in vitro, and it is hypothesized that plant-produced flavones prevent the induction of alternative oxidase in nature, thus inhibiting alternative respiration $(22,31)$. However, alternative respiration is still important because it may strongly impact results of in vitro assays, leading to inaccurate assessments of fungicide sensitivity in vitro. The chemical salicylhydroxamic acid (SHAM) is used in QoI in vitro fungicide testing to prevent fungal pathogens from using an alternative respiration mechanism (22). The ability of A. rabiei to use alternative respiration has not been reported.

The objectives of this research were to (i) determine whether A. rabiei isolates are capable of using alternative respiration during in vitro fungicide sensitivity assays and (ii) establish the baseline sensitivities of A. rabiei isolates to azoxystrobin, pyraclostrobin, and boscalid using isolates collected prior to exposure to QoI and boscalid fungicides.

\section{MATERIALS AND METHODS}

Collection of isolates of $A$. rabiei. Fifty-one A. rabiei isolates were obtained from the Ascochyta collection in the United States Department of AgricultureAgricultural Research Service collection in Pullman, WA (Table 1). These A. rabiei isolates were collected prior to the registrations of QoI fungicides and boscalid in the United States, and represent a true baseline group with no possible exposure to any QoI chemistry or boscalid. An additional 20 isolates of A. rabiei were used to establish the baseline for boscalid (Table 1); these isolates were collected prior to the use of boscalid in U.S. chickpea fields. Each isolate was preserved for long-term storage by plating $2 \mu \mathrm{l}$ of conidial suspension onto individual plates of potato dextrose agar (PDA) (Difco Laboratories, Detroit) with Whatman no. 1 filter paper cut into small strips, sterilized, and placed on the agar surface. Each isolate was grown in a growth chamber for 14 to 21 days under a diurnal cycle $(12 \mathrm{~h}$ of light and $12 \mathrm{~h}$ of dark) at $20 \pm 2^{\circ} \mathrm{C}$, at which time the filter paper was covered with mycelia. Filter papers were removed from the agar surface using sterile forceps and dried for approximately $18 \mathrm{~h}$ in a laminar flow hood. Filter papers were placed in sterile $15-\mathrm{ml}$ centrifuge tubes; tubes were sealed with Parafilm and stored at $-20^{\circ} \mathrm{C}$.

Preparation of $A$. rabiei isolates for conidia germination assays. All A. rabiei isolates in all experiments were prepared using the following methods adapted from Pasche et al. (24). Sterile $0.05 \%$ Tween 20 (Sigma-Aldrich, St. Louis) was added to 7day-old cultures of A. rabiei and the conidia were dislodged from the agar using a sterile glass rod. The resulting conidial suspension was adjusted to $2 \times 10^{5}$ conidia/ml using a hemacytometer. A conidial suspension $(100 \mu \mathrm{l})$ of each isolate was pipetted onto each of two replicate petri

Table 1. Collection information for baseline isolates of Ascochyta rabiei from chickpea

\begin{tabular}{lll}
\hline Year $^{\mathbf{a}}$ & \multicolumn{1}{c}{ Location } & \multicolumn{1}{c}{ Isolates $^{\mathbf{b}}$} \\
\hline 1983 & Pullman, WA & AR465, AR468, AR471, AR477 \\
1984 & Genesee, ID & AR714, AR721 \\
1984 & Pullman, WA & AR439, AR441, AR444, AR445, AR456 \\
1987 & Genesee, ID & AR401, AR402, AR403, AR404, AR405, AR406, AR407, \\
& & AR408, AR453 \\
1987 & Kendrick, ID & AR430, AR437 \\
1987 & Lapwai, ID & AR414, AR415, AR416, AR417, AR418, AR419, AR420 \\
1987 & Nez Pierce County, ID & AR409, AR410, AR411, AR413 \\
1994 & Genesee, ID & AR423, AR424, AR425, AR427, AR428 \\
1995 & Albion, WA & AR590 \\
1995 & Genesee, ID & AR588, AR598, AR601, AR604 \\
1995 & LaGrande, OR & AR625 \\
1995 & Steptoe, WA & AR666, AR668 \\
1995 & Waitsburg, WA & AR616, AR617 \\
1995 & Walla Walla WA & AR618, AR660, AR661 \\
2002 & Fresno, CA & C2-1, C2-2, C2-4 \\
2002 & Genesee, ID & B3-15, B3-25, B3-45 \\
2002 & Pullman, WA & A2-25, A3-15, A4-15, CAB01-4 \\
2003 & Culdesac, ID & 03-C1-3 \\
2003 & Genesee, ID & 03-A1, 03-A2, 03-A3, 03-B1, 03-B2, 03-B3, 03-E3, 03-F1, 03-F4 \\
\hline
\end{tabular}

a Year collected. All isolates were used as boscalid fungicide baseline isolates, but only isolates collected prior to 2002 were used as azoxystrobin and pyraclostrobin fungicide baseline isolates.

b Isolates with an "AR" designation were obtained from Dr. Frank Dugan, United States Department of Agriculture-Agricultural Research Service (USDA-ARS), Pullman, WA. All other isolates were obtained from Dr. Weidong Chen, USDA-ARS, Pullman, WA. plates ( 60 by $15 \mathrm{~mm}$ ). Plates were held at $19^{\circ} \mathrm{C}$ for $18 \mathrm{~h}$ in the dark. Following incubation, 100 conidia per plate were visually assessed microscopically $(\times 100$ magnification) and evaluated for germination. A conidium was considered to be germinated if the germ tube was at least as long as the length of the conidium.

Effect of SHAM on conidia germination. The effect of SHAM (Sigma-Aldrich) at a concentration of $100 \mu \mathrm{g} / \mathrm{ml}$ on $\mathrm{A}$. $\mathrm{ra}$ biei conidial germination was examined in a preliminary experiment. Ten isolates (AR401, AR402, AR418, AR430, AR477, AR604, AR660, AR666, AR668, and AR721) were selected randomly to test on PDA amended with SHAM at $100 \mu \mathrm{g} / \mathrm{ml}$ and nonamended PDA. Random selection of the isolates was done using the RAND function in Microsoft Excel 2003 software (Microsoft Corp., Redmond, WA). For this experiment, a stock solution of SHAM was prepared by adding $100 \mathrm{mg}$ of SHAM for each $1 \mathrm{ml}$ of methanol. The final concentration of both acetone and methanol in media amended with fungicide and nonamended media was $0.1 \%$ by volume. All amendments were filter sterilized and added to the autoclaved media after it had cooled to $55^{\circ} \mathrm{C}$. The experiment was arranged as a completely randomized design (CRD) with two replicate plates of each isolate. The experiment was repeated once in an additional run, and data were analyzed using the general linear model procedure (PROC GLM) in SAS (version 8.2; SAS Institute, Inc., Cary, NC). Data from each run were analyzed separately first to compute variances, and a two-tailed $F$ test for equality of variances was conducted to determine whether trials could be combined. In the combined analysis, the lack of significant $(P \leq 0.05)$ run and runisolate interactions were used additionally to determine whether runs could be combined. If run or run-isolate interactions were not significant, then run was dropped from the model and an analysis of variance was calculated.

Effect of SHAM and azoxystrobin on conidia germination. Nine isolates (AR401, AR402, AR418, AR477, AR604, AR660, AR666, AR668, and AR721) were randomly selected and tested to compare the effect of azoxystrobin on in vitro conidial germination with and without the addition of SHAM to the media. This experiment was conducted to determine whether alternative respiration is induced in A. rabiei by the presence of a respiration-inhibiting fungicide such as azoxystrobin. Isolates were prepared for plating using the methods described previously, with the addition of technical-grade azoxystrobin (97.6\% a.i.; Syngenta Crop Protection) to the media. A stock solution of azoxystrobin was prepared at a concentration of $100 \mathrm{mg} / \mathrm{ml}$ in acetone. Serial dilutions of the stock solution were prepared in acetone and conidia germination was as- 
sessed on PDA amended with azoxystrobin at $0,0.001,0.01,0.1,1$, and $10 \mu \mathrm{g} / \mathrm{ml}$. Conidial germination also was assessed on PDA amended with the six concentrations of azoxystrobin and SHAM at $100 \mu \mathrm{g} / \mathrm{ml}$ dissolved in methanol. All amendments were filter sterilized and added to the autoclaved media after it had cooled to $55^{\circ} \mathrm{C}$. Conidia were incubated and percent conidial germination was assessed as described previously. Conidial germination for each of the replicate plates was converted to percent inhibition compared with the untreated control by: 100 - ([percent germination of fungicide-amended $] /[$ mean percent germination of non-amended]). The fungicide concentration that effectively inhibited conidial germination by $50 \%$ of the untreated control $\left(\mathrm{EC}_{50}\right)$ was determined for each isolate by linear interpolation using the two concentrations that bracketed $50 \%$. This experiment was arranged as a CRD with two replicate plates per isolate, and the experiment was repeated once in an additional run. Data were analyzed using PROC GLM in SAS (version 8.2) as described in the previous section. Least square means $t$ tests (PDIFF option in SAS) were used to compare $\mathrm{EC}_{50}$ values of individual $A$. rabiei conidia on SHAM-amended PDA versus nonamended PDA.

Determination of baseline $\mathbf{E C}_{50}$ values. Stock solutions of technical-grade formulations of azoxystrobin (97.6\% a.i.; Syngenta Crop Protection), pyraclostrobin (99\% a.i.; BASF Corporation), and boscalid (95\% a.i.; BASF Corporation) were prepared at concentrations of 100 $\mathrm{mg} / \mathrm{ml}$ in acetone. Serial dilutions in acetone were prepared for each fungicide. Fungicide sensitivity was determined by evaluating A. rabiei conidial germination on PDA amended with each fungicide at 0 , $0.001,0.01,0.1,1$, and $10 \mu \mathrm{g} / \mathrm{ml}$ and SHAM at $100 \mu \mathrm{g} / \mathrm{ml}$ dissolved in methanol. The final concentration of both acetone and methanol in media amended with fungicide and nonamended media was $0.1 \%$ by volume. All amendments were filter sterilized and added to the autoclaved media after it had cooled to $55^{\circ} \mathrm{C}$.

A. rabiei cultures were prepared for fungicide sensitivity testing using the methods described in the previous sections. Conidial germination and conversion of germination to percent inhibition was assessed and determined as described previously. $\mathrm{EC}_{50}$ values were determined for each isolate and fungicide.

Baseline isolates were tested across seven trials due to time and space constraints. In all, 6 to 12 isolates were tested in each trial along with an internal control isolate (AR666) that was used to determine reproducibility of the trials. An assay reproducibility test described by Wong and Wilcox (32) was used to validate the reproducibility of each of the seven trials conducted. For this reproducibility test, the internal control isolate (AR666) was tested in another experiment that was repeated 10 times in different runs, and the assay reproducibility calculations used by Wong and Wilcox (32) were applied to the resulting $\mathrm{EC}_{50}$ values, in which the mean, standard error, and $95 \%$ confidence intervals were calculated for the internal control isolate. For each of the seven trials conducted to determine baseline $\mathrm{EC}_{50}$ values, if the $\mathrm{EC}_{50}$ value of the internal control isolate did not fall within the $95 \%$ confidence interval, then that specific trial was repeated until the internal control fell within the $95 \%$ confidence interval. Isolates were arranged in a CRD with two replicate plates per isolate. Each of the seven trials was repeated once over time in an additional run. A two-tailed $F$ test was conducted as previously described to determine whether variances of the two runs were equal. In the combined analysis of the two runs, the lack of significant $(P \leq$ 0.05 ) run and run-isolate interactions was used additionally to determine whether runs could be combined. If run or runisolate interactions were not significant, then run was dropped from the model and an analysis of variance was calculated. The baseline sensitivity distributions of each fungicide were tested for normality using the Shapiro-Wilk test (PROC UNIVARIATE NORMAL) in SAS (version 8.2). Associations among baseline sensitivities of each fungicide were evaluated using Pearson correlation analysis (PROC CORR) in SAS (version 8.2).

\section{RESULTS}

Effect of SHAM on conidial germination. Analysis of the effects of SHAM on conidial germination indicated no significant isolate-SHAM interaction $(P=$ $0.3251)$ and no effect of SHAM on $A$. rabiei conidial germination $(P=0.4495)$. Mean percent germination for conidia on PDA amended with $100 \mu \mathrm{g} / \mathrm{ml}$ of SHAM was $98.3 \%$, compared with $98.5 \%$ for conidia on nonamended PDA. Because SHAM alone was determined not to influence conidial germination, it was used in subsequent trials.
Effect of SHAM and azoxystrobin on conidial germination. Separate analysis of experiments conducted to determine the impact of SHAM on conidial germination in the presence and absence of azoxystrobin produced equal variances according to an $F$ test; therefore, experiments were combined for analysis. Analysis of $\mathrm{EC}_{50}$ values of the nine isolates exposed to azoxystrobin with and without SHAM at $100 \mu \mathrm{g} / \mathrm{ml}$ indicated that the main effects of isolate and SHAM were significant $(P=$ 0.0003 and 0.0001 , respectively) and the interaction of isolate-SHAM was significant $(P=0.0004)$. In five of the nine isolates tested (AR401, AR402, AR418, $\mathrm{AR668}$, and $\mathrm{AR} 721), \mathrm{EC}_{50}$ values were significantly $(P \leq 0.05)$ greater when SHAM was not included in the fungicideamended media (Table 2). No other significant differences were found.

Determination of baseline $\mathbf{E C}_{50}$ values. Analyses of in vitro fungicide sensitivity trials were conducted and the $F$ test for homogeneity of variance indicated that variances were equal, and no significant $(P$ $\leq 0.05$ ) interactions were observed between run and other factors. Therefore, data from runs were combined to determine the mean $\mathrm{EC}_{50}$ values for each isolate-fungicide combination. The range of $\mathrm{EC}_{50}$ values for isolates exposed to azoxystrobin was 0.0182 to $0.0338 \mu \mathrm{g} / \mathrm{ml}$, and the mean value was $0.0272 \mu \mathrm{g} / \mathrm{ml}$ (Fig. 1). The azoxystrobin, $\mathrm{EC}_{50}$ values were normally distributed $(P=0.0922)$. For pyraclostrobin, the range of $\mathrm{EC}_{50}$ values of the isolates was 0.0012 to 0.0033 $\mu \mathrm{g} / \mathrm{ml}$, and the mean value was 0.0023 $\mu \mathrm{g} / \mathrm{ml}$ (Fig. 2). The pyraclostrobin $\mathrm{EC}_{50}$ values were normally distributed $(P=$ 0.2787). The range of $\mathrm{EC}_{50}$ values for isolates exposed to boscalid was 0.0177 to $0.4960 \mu \mathrm{g} / \mathrm{ml}$, and the mean value was $0.1903 \mu \mathrm{g} / \mathrm{ml}$ (Fig. 3). The boscalid $\mathrm{EC}_{50}$ values did not have a normal distribution $(P=0.0226)$. Pearson correlation analysis indicated that there was a significant $(P=$ 0.0001) relationship between azoxystrobin and pyraclostrobin baseline sensitivities $(r=0.53)$, and no other relationships were significant.

Table 2. Comparison of azoxystrobin effective concentration at which $50 \%$ of conidial germination was inhibited $\left(\mathrm{EC}_{50}\right)$ values $(\mu \mathrm{g} / \mathrm{ml})$ of nine Ascochyta rabiei baseline isolates in salicylhydroxamic acid (SHAM)-amended potato dextrose agar and nonamended potato dextrose agar

\begin{tabular}{lccc}
\hline Isolate & SHAM-amended & Nonamended & $\boldsymbol{P}_{\text {value }}$ \\
\hline AR401 & 0.0277 & 0.0509 & 0.0024 \\
AR402 & 0.0287 & 0.0435 & 0.0237 \\
AR418 & 0.0338 & 0.0566 & 0.0026 \\
AR477 & 0.0251 & 0.0306 & 0.3307 \\
AR604 & 0.0264 & 0.0314 & 0.3763 \\
AR660 & 0.0335 & 0.0414 & 0.1728 \\
AR666 & 0.0238 & 0.0340 & 0.0911 \\
AR668 & 0.0209 & 0.0675 & 0.0001 \\
AR721 & 0.0232 & 0.0399 & 0.0136 \\
Mean & 0.0269 & 0.0439 & 0.0003
\end{tabular}

a $P$ value for individual isolates were determined using least-square means $t$ tests; $P$ value for comparison of overall isolate means of SHAM-amended and nonamended was determined from an $F$ test. 


\section{DISCUSSION}

The chemical SHAM is used in QoI in vitro fungicide testing to prevent fungal pathogens from using an alternative respi- ration mechanism to bypass complex III in the mitochondrial pathway (the QoI fungicide binding site), which may allow the fungus to germinate in the presence of

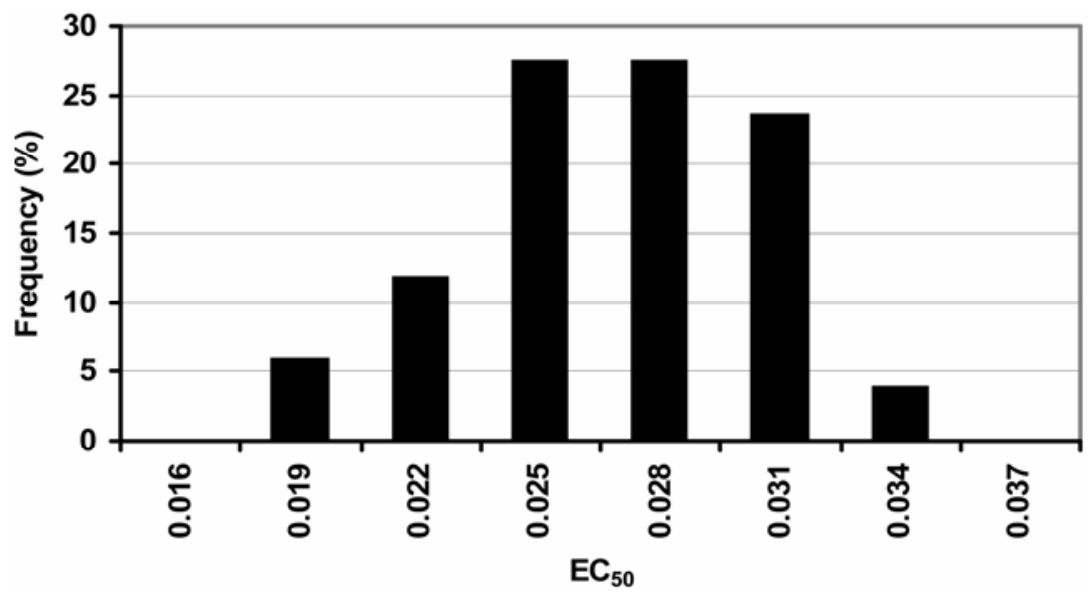

Fig. 1. Frequency distribution of effective fungicide concentration at which $50 \%$ of conidial germination was inhibited $\left(\mathrm{EC}_{50}\right)$ values $(\mu \mathrm{g} / \mathrm{ml})$ for 51 baseline isolates of Ascochyta rabiei to azoxystrobin. Individual isolates are grouped in class intervals of $0.003 \mu \mathrm{g} / \mathrm{ml}$; values on the $\mathrm{X}$-axis indicate the midpoint of the interval.

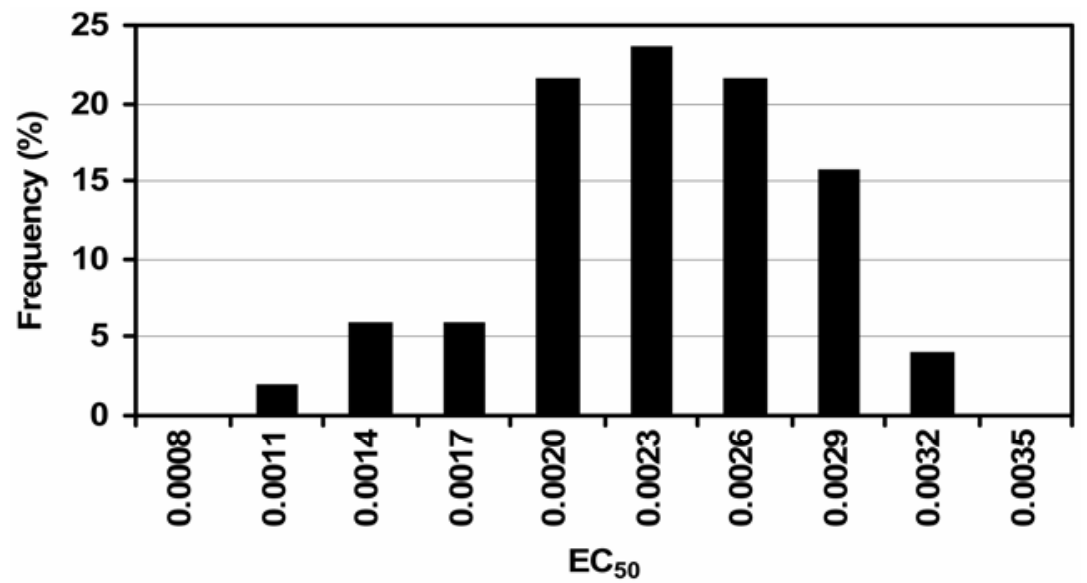

Fig. 2. Frequency distribution of effective fungicide concentration at which $50 \%$ of conidial germination was inhibited $\left(\mathrm{EC}_{50}\right)$ values $(\mu \mathrm{g} / \mathrm{ml})$ for 51 baseline isolates of Ascochyta rabiei to pyraclostrobin. Individual isolates are grouped in class intervals of $0.0003 \mu \mathrm{g} / \mathrm{ml}$; values on the $\mathrm{X}$-axis indicate the midpoint of the interval.

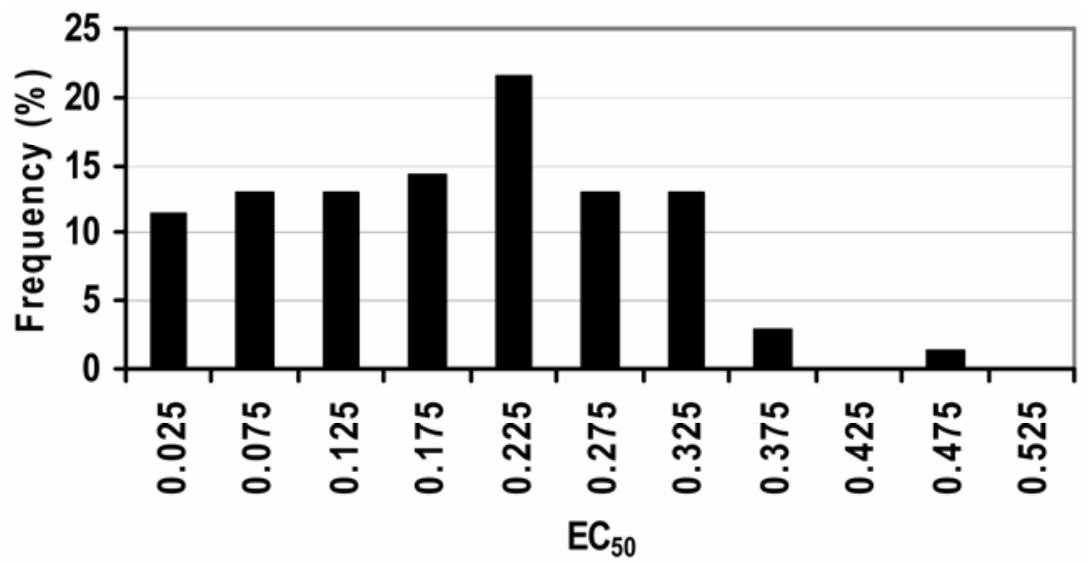

Fig. 3. Frequency distribution of effective fungicide concentration at which $50 \%$ of conidial germination was inhibited $\left(\mathrm{EC}_{50}\right)$ values $(\mu \mathrm{g} / \mathrm{ml})$ for 71 baseline isolates of Ascochyta rabiei to boscalid. Individual isolates are grouped in class intervals of $0.05 \mu \mathrm{g} / \mathrm{ml}$; values on the X-axis indicate the midpoint of the interval.

high levels of QoI fungicides $(22,35)$. The effects of SHAM and azoxystrobin were tested with the pathogen Alternaria alternata (17). In that study, no significant differences were observed between $\mathrm{EC}_{50}$ values when SHAM was included with the fungicide and when it was omitted, although the mean $\mathrm{EC}_{50}$ value was $2 \times$ higher when SHAM was omitted than when SHAM was included in the fungicideamended media $(0.12$ versus $0.06 \mu \mathrm{g} / \mathrm{ml})$. In contrast, conidial germination of baseline isolates of Pyricularia grisea were inhibited by azoxystrobin and trifloxystrobin at fungicide concentrations of 0.1 $\mu \mathrm{g} / \mathrm{ml}$ when SHAM was added to conidial suspensions at a rate of $100 \mu \mathrm{g} / \mathrm{ml}$ (31); however, when SHAM was not included in conidial suspensions, $\mathrm{EC}_{50}$ values of baseline isolates did not differ significantly from the $\mathrm{EC}_{50}$ values of resistant isolates (31). In vitro QoI fungicide resistance due to alternative respiration also has been demonstrated in Venturia inaequalis and Septoria tritici $(22,35)$. The current study indicates that there are isolates in the $A s$ cochyta rabiei population that may be able to use alternative respiration to bypass the QoI fungicide binding site, leading to higher in vitro $\mathrm{EC}_{50}$ values. These skewed $\mathrm{EC}_{50}$ values can, in turn, lead to inaccurate assessments of fungicide sensitivity in the pathogen population. Ziogas et al. (35), showed that alternative respiration occurs in both the wild-type and mutant strain of S. tritici. This information, along with our results, indicates that isolates need not be previously exposed to QoI fungicides to utilize alternative respiration. Therefore, SHAM at $100 \mu \mathrm{g} / \mathrm{ml}$ should be included in all in vitro QoI fungicide testing conducted with A. rabiei.

A. rabiei isolates exhibited a narrow range of $\mathrm{EC}_{50}$ values for azoxystrobin similar to other fungal pathogens with baselines previously established (Fig. 1). Baseline $\mathrm{EC}_{50}$ values of conidial isolates of $P$. grisea for azoxystrobin ranged from 0.015 to $0.064 \mu \mathrm{g} / \mathrm{ml}$, with a mean of $0.0290 \mu \mathrm{g} / \mathrm{ml}$ (31). Similarly, in Alternaria solani, $\mathrm{EC}_{50}$ values for baseline isolates for azoxystrobin ranged from 0.011 to 0.090 $\mu \mathrm{g} / \mathrm{ml}$, with a mean of $0.038 \mu \mathrm{g} / \mathrm{ml}$ (24). Isolates of Erysiphe graminis f. sp. tritici also had similar values for azoxystrobin, ranging from 0.022 to $0.235 \mu \mathrm{g} / \mathrm{ml}$ (6).

Few examples exist in the literature reporting baseline sensitivity of fungal pathogens to pyraclostrobin. $\mathrm{EC}_{50}$ values for $A$. solani baseline isolates indicate that the fungus is 10 times more sensitive to pyraclostrobin than azoxystrobin (24), which is similar to the Ascochyta rabiei isolates tested in our research trials. Similarly, $\mathrm{EC}_{50}$ values for Uncinula necator sensitivity to pyraclostrobin ranged from 0.0016 to $0.010 \mu \mathrm{g} / \mathrm{ml}$, with a mean of $0.0044 \mu \mathrm{g} / \mathrm{ml}$ (33), which is comparable with the $\mathrm{EC}_{50}$ values shown for A. rabiei in our study. In a study on fungicide sensitivi- 
ties of citrus pathogens, Mondal et al. (17) reported baseline sensitivities of five fungal pathogens (Colletotrichum acutatum, Alternaria alternata, Elsinoe fawcettii, Diaporthe citri, and Mycosphaerella citri) to pyraclostrobin, and mean $\mathrm{EC}_{50}$ values for isolate sensitivity to pyraclostrobin was over $8 \times$ higher for each of the five citrus pathogens than for Ascochyta rabiei. This could be attributed to the fact that Mondal et al. (17) used inhibition of mycelial growth to determine $\mathrm{EC}_{50}$ values, rather than conidial germination inhibition. Because QoI fungicides are powerful inhibitors of spore germination (2), an assay based on spore germination is likely a better method for determining sensitivity of fungi to this chemistry. The difference in methodology could partially explain why baseline isolates of A. rabiei are more sensitive to pyraclostrobin than the citrus pathogens reported. A preliminary finding of resistance to azoxystrobin and pyraclostrobin in Didymella rabiei was reported in Canada (8). This report of QoI resistance in D. rabiei was based on mycelial growth inhibition without the addition of SHAM (8). A more definitive conclusion of the sensitivity of the Canadian isolates to QoI fungicides would be obtained if these isolates were additionally tested using conidial germination with the addition of SHAM and compared with the azoxystrobin baseline sensitivity developed. As discussed previously, our research indicates the importance of using SHAM when measuring A. rabiei sensitivity to QoI fungicides in vitro.

A few reports of in vitro fungal pathogen sensitivities to boscalid are available. In Spilocaea oleagina, $\mathrm{EC}_{50}$ values for conidial germination of isolates exposed to boscalid ranged from 0.005 to $0.5 \mu \mathrm{g} / \mathrm{ml}$, with a mean of $0.031 \mu \mathrm{g} / \mathrm{ml}$ (19). In Alternaria solani, $\mathrm{EC}_{50}$ values of boscalid ranged from 0.275 to $2.70 \mu \mathrm{g} / \mathrm{ml}$, with a mean of $0.6878 \mu \mathrm{g} / \mathrm{ml}$ (23). In A. alternata, $\mathrm{EC}_{50}$ values of boscalid in isolates never before exposed to boscalid ranged from 0.089 to $3.435 \mu \mathrm{g} / \mathrm{ml}$, with a mean of $1.515 \mu \mathrm{g} / \mathrm{ml}$ (1). Based on conidial germination of Botrytis cinerea, Stammler and Speakman (28) reported that $\mathrm{EC}_{50}$ values of boscalid ranged from 0.01 to 0.21 $\mu \mathrm{g} / \mathrm{ml}$, with a mean of $0.06 \mu \mathrm{g} / \mathrm{ml}$, while Zhang et al. (34) reported $\mathrm{EC}_{50}$ values of 0.02 to $1.68 \mu \mathrm{g} / \mathrm{ml}$, with a mean of 0.42 $\mu \mathrm{g} / \mathrm{ml}$. Zhang et al. (34) also reported $\mathrm{EC}_{50}$ values of boscalid based on mycelial growth of $B$. cinerea ranging from 0.09 to $3.69 \mu \mathrm{g} / \mathrm{ml}$, with a mean of $1.07 \mu \mathrm{g} / \mathrm{ml}$. The comparison of conidial germination and mycelial growth of $B$. cinerea in the Zhang et al. study (34) indicated that conidial germination was more sensitive to boscalid than mycelial growth. Although these pathogens do not have similar mean $\mathrm{EC}_{50}$ values compared with Ascochyta rabiei $(0.1903 \mu \mathrm{g} / \mathrm{ml})$, they do exhibit the same broad range in boscalid $\mathrm{EC}_{50}$ values displayed by individual $A$. rabiei isolates $(0.0177$ to $0.4960 \mu \mathrm{g} / \mathrm{ml})$.

The $\mathrm{EC}_{50}$ values for $A$. rabiei baseline isolates to azoxystrobin and pyraclostrobin were similar in that both had relatively narrow ranges in values, which were represented by two- and threefold differences in sensitivity to these fungicides for the majority of isolates, respectively (Figs. 1 and 2 ). Additionally, azoxystrobin and pyraclostrobin baseline sensitivities both were distributed normally, and there was a significant, positive relationship between azoxystrobin and pyraclostrobin sensitivity values. The narrow distribution of pyraclostrobin $\mathrm{EC}_{50}$ values and 12-fold difference in mean $\mathrm{EC}_{50}$ values when compared with azoxystrobin indicate that pyraclostrobin has higher intrinsic activity against A. rabiei than either azoxystrobin or boscalid (Figs. 1 to 3 ). This same phenomenon also has been found previously in both Alternaria solani and $U$. necator. In each case, isolates were 10 times more sensitive to pyraclostrobin than azoxystrobin as indicated by $\mathrm{EC}_{50}$ values (24,33). The distribution of Ascochyta rabiei $\mathrm{EC}_{50}$ values to boscalid had a broad range, which was represented by a 28 -fold difference in sensitivity to this fungicide. This broad range of $\mathrm{EC}_{50}$ values is a warning that the potential of A. rabiei developing resistance to boscalid is present (12).

Although information on fungicide sensitivity of ascospores of the teleomorph $D$. rabiei would be valuable for comparison purposes, A. rabiei conidia are the primary target of QoI fungicide applications to prevent repeated cycles of conidial infection. Conidia of A. rabiei often are considered to be secondary inoculum; however, conidia also can serve as primary inoculum by overwintering on infected debris and as inoculum on infected seed $(9,13)$. The conidial stage of other ascomycetes has been used previously to assess QoI fungicide sensitivity in spore germination assays $(6,21,29,31,33)$. Sensitivity tests of Venturia inaequalis isolates to flusilazole indicated that ascospores were more sensitive than conidia, but both were suitable for fungicide resistance monitoring (25). Fungicide sensitivities of $A$. rabiei conidia and ascospores were not compared in our research; however, using conidia of $A$. rabiei to establish baseline fungicide sensitivity levels and in future fungicide resistance monitoring should provide an accurate assessment.

Fungal plant pathogens that are able to generate variation through sexual recombination and that have a polycyclic disease cycle have an increased risk of developing resistance to fungicides $(4,11,12,14)$. Sexual recombination occurs in $A$. rabiei ( $D$. rabiei) and it has a polycyclic disease cycle. Due to these risk factors present in $A$. rabiei, and the high risk of resistance development in QoI and carboximide fungicides, baseline sensitivity developed in this research will be important in monitoring $A$. rabiei populations to help ensure efficacy of current fungicide spray programs. A fungicide resistance A. rabiei monitoring program recently established at North Dakota State University, Fargo, is using these fungicide sensitivity baselines to measure for shifts in sensitivity of $A$. $r a$ biei isolates exposed to these fungicides.

\section{ACKNOWLEDGMENTS}

This project was funded by a grant from the United States Department of AgricultureCooperative State Research, Education, and Extension Service Cool Season Food Legume Research Program. We thank R. Horsley and C. Doetkott for statistical consultation; D. Liane, B. Tarang, and N. Zahradka for technical assistance; and BASF Corporation and Syngenta Crop Protection for providing the technical-grade formulations of the fungicides.

\section{LITERATURE CITED}

1. Avenot, H. F., and Michailides, T. J. 2007. Resistance to boscalid fungicide in Alternaria alternata isolates from pistachio in California. Plant Dis. 91:1345-1350.

2. Bartlett, D. W., Clough, J. M., Godwin, J. R., Hall, A. A., Hamer, M., and Parr-Dobrzanski, B. 2002. The strobilurin fungicides. Pest Manage. Sci. 58:649-662.

3. BASF Corporation. 2003. Endura Technical Information Bulletin. NVA 02-10-201-3001, BASF Corporation, Research Triangle Park, NC.

4. Brent, K. J., and Hollomon, D. W. 1998. Fungicide resistance: the assessment of risk FRAC Monogr. No. 2. Global Crop Protection Federation, Brussels.

5. Chen, W., Coyne, C. J., Peever, T. L., and Muehlbauer, F. J. 2004. Characterization of chickpea differentials for pathogenicity assay of Ascochyta blight and identification of chickpea accessions resistant to Didymella rabiei. Plant Pathol. 53:759-769.

6. Chin, K. M., Chavaillaz, D., Kaesbohrer, M., Staub, T., and Felsenstein, F. G. 2001. Characterizing resistance risk of Erysiphe graminis $\mathrm{f}$ sp. tritici to strobilurins. Crop Prot. 20:87-96.

7. Chongo, G., Gossen, B. D., Buchwaldt, L., Adhikari, T., and Rimmer, S. R. 2004. Genetic diversity of Ascochyta rabiei in Canada. Plant Dis. 88:4-10.

8. Gossen, B. D., and Anderson, K. L. 2004. First report of resistance to strobilurin fungicides in Didymella rabiei. (Abstr.) Can. J. Plant Pathol. 26:411.

9. Gossen, B. D., and Miller, P. R. 2004. Survival of Ascochyta rabiei in chickpea residue on the Canadian prairies. Can. J. Plant Pathol 26:142-147.

10. Grasso, V., Palermo, S., Sierotzki, H., Garibaldi, A., and Gisi, U. 2006. Cytochrome $b$ gene structure and consequences for resistance to $\mathrm{Q}_{\mathrm{o}}$ inhibitor fungicides in plant pathogens. Pest Manage. Sci. 62:465-472.

11. Hewitt, H. G. 1998. Fungicides in Crop Protection. CAB International, New York.

12. Jutsum, A. R., Heaney, S. P., Perrin, B. M., and Wege, P. J. 1998. Pesticide resistance: assessment of risk and the development and implementation of effective management strategies. Pestic. Sci. 54:435-446.

13. Kaiser, W. J., Okhovat, M., and Mossahebi, G H. 1973. Effect of seed-treatment fungicides on control of Ascochyta rabiei in chickpea seed infected with the pathogen. Plant Dis. Rep. 57:742-746.

14. Kendall, S. J., and Hollomon, D. W. 1998 Fungicide resistance. Pages 87-108 in: Fungicidal Activity: Chemical and Biological Approaches to Plant Protection. D. Hutson and J. 
Miyamoto, eds. John Wiley and Sons, New York.

15. Kim, Y. S., Dixon, E. W., Vincelli, P., and Farman, M. L. 2003. Field resistance to strobilurin (QoI) fungicides in Pyricularia grisea caused by mutations in the mitochondrial cytochrome b gene. Phytopathology 93:891-900.

16. Ma, Z., Felts, D., and Michailides, T. J. 2003. Resistance to azoxystrobin in Alternaria isolates from pistachio in California. Pestic. Biochem. Physiol. 77:66-74.

17. Mondal, S. N., Bhatia, A., Shilts, T., and Timmer, L. W. 2005. Baseline sensitivities of fungal pathogens of fruit and foliage of citrus to azoxystrobin, pyraclostrobin, and fenbuconazole. Plant Dis. 89:1186-1194.

18. Nene, Y. L., and Reddy, M. V. 1987. Chickpea diseases and their control. Pages 233-270 in: The Chickpea. M. C. Saxena and K. B. Singh, eds. CAB International, Oxon, UK.

19. Obanor, F. O., Walter, M., Jones, E. E., and Jaspers, M. V. 2005. In vitro effects of fungicides on conidium germination of Spilocaea oleagina, the cause of olive leaf spot. Pages 278-282 in: New Zealand Plant Prot. Conf. Proc. Vol. 58. New Zealand Plant Protection Society, Rotorua, New Zealand.

20. Olaya, G., and Holm, A. 2001. Sensitivity of Didymella bryoniae to azoxystrobin. (Abstr.) Phytopathology 91:S67.

21. Olaya, G., and Köller, W. 1999. Baseline sensitivities of Venturia inaequalis populations to the strobilurin fungicide kresoxim-methyl. Plant Dis. 83:274-278.

22. Olaya, G., and Köller, W. 1999. Diversity of kresoxim-methyl sensitivities in baseline populations of Venturia inaequalis. Pestic. Sci. 55:1083-1088.

23. Pasche, J. S., Piche, L. M., and Gudmestad, N. C. 2005. Effect of the F129L mutation in $\mathrm{Al}$ ternaria solani on fungicides affecting mitochondrial respiration. Plant Dis. 89:269-278.

24. Pasche, J. S., Wharam, C. M., and Gudmestad, N. C., 2004. Shift in sensitivity of Alternaria solani in response to $\mathrm{Q}_{\mathrm{o}} \mathrm{I}$ fungicides. Plant Dis. 88:181-187.

25. Philion, V. 2007. A comparison of fungicide resistance monitoring techniques currently in use for Venturia inaequalis. (Abstr.) Phytopathology 97:S93.

26. Russell, P. E. 2004. Sensitivity baselines in fungicide resistance research management. FRAC Monogr. No. 3. Crop Life International, Brussels.

27. Shtienberg, D., Vintal, H., Brener, S., and Retig, B. 2000. Rational management of $\mathrm{Di}$ dymella rabiei in chickpea by integration of genotype resistance and postinfection application of fungicides. Phytopathology 90:834842 .

28. Stammler, G., and Speakman, J. 2006. Microtiter method to test the sensitivity of Botrytis cinerea to boscalid. J. Phytopathol. 154:508510.
29. Stevenson, K. L., Langston, D. B., Jr., and Seebold, K. W. 2004. Resistance to azoxystrobin in the gummy stem blight pathogen documented in Georgia. Online. Plant Health Progress doi:10.1094/PHP-2004-1207-01-RS.

30. Trapero-Casas, A., and Kaiser, W. J. 1992. Influence of temperature, wetness period, plant age, and inoculum concentration on infection and development of Ascochyta blight of chickpea. Phytopathology 82:589-596.

31. Vincelli, P., and Dixon, E. 2002. Resistance to $\mathrm{Q}_{0} \mathrm{I}$ (strobilurin-like) fungicides in isolates of Pyricularia grisea from perennial ryegrass. Plant Dis. 86:235-240.

32. Wong, F. P., and Wilcox, W. F. 2000. Distribution of baseline sensitivities to azoxystrobin among isolates of Plasmopara viticola. Plant Dis. 84:275-281.

33. Wong F. P., and Wilcox, W. F. 2002. Sensitivity to azoxystrobin among isolates of Uncinula necator: baseline distribution and relationship to myclobutanil sensitivity. Plant Dis. 86:394 404.

34. Zhang, C. Q., Yuan, S. K., Sun, H. Y., Qi, Z Q., Zhou, M. G., and Zhu, G. N. 2007. Sensitivity of Botrytis cinerea from vegetable greenhouses to boscalid. Plant Pathol. 56:646653.

35. Ziogas, B. N., Baldwin, B. C., and Young, J. E. 1997. Alternative respiration: a biochemical mechanism of resistance to azoxystrobin (ICIA 5504) in Septoria tritici. Pestic. Sci. 50:28-34. 